\title{
Large-scale modelling of environments favourable for dry lightning occurrence
}

\author{
$\underline{\text { Andrew J. Dowdy }}^{\text {a }}$ \\ ${ }^{a}$ Bureau of Meteorology, Docklands, Victoria \\ Email: $\underline{\text { a.dowdy@bom.gov.au }}$
}

\begin{abstract}
Lightning that occurs with relatively little accompanying rainfall, known as dry lightning, is one of the main ignition sources for wildfires throughout the world. A method for indicating large-scale environments favourable to the occurrence of dry lightning is examined here. The method is designed to be of coarse spatial and temporal scales, for potential application to global climate models. It is developed based on atmospheric conditions obtained from reanalyses, in conjunction with lightning observations from a ground-based network of sensors during the period from 2002 to 2013. The method is applied to global climate model simulations to examine the influence of increasing atmospheric greenhouse gas concentrations on the projected frequency of occurrence of dry lightning activity in Australia. The results indicate considerable seasonal and spatial variability of the projected changes in environments favorable to dry lightning occurrence. Given the importance of dry lightning to the area burnt by fires, long-term changes in dry lightning activity could potentially have a range of significant impacts, including in relation to fire regimes, ecology, fire emissions and emergency management.
\end{abstract}

Keywords: Lightning, thunderstorms, convection, climate change, bushfire, storms 
Dowdy, Large-scale modelling of environments favourable for dry lightning occurrence

\section{INTRODUCTION}

Fires ignited by lightning typically burn a larger area on average than fires from other ignition sources, attributable to the fact that they can occur more frequently in spatial and temporal clusters and in more remote areas that are difficult for response personnel to access than fires not ignited by lightning [Wotton et al. 2005; Kasischke et al. 2006; Dowdy and Mills 2012a]. The probability that lightning will result in a sustained fuel ignition is highly dependent on fuel moisture and studies in different parts of the world have found that the chance of a bushfire (i.e. wildfire) occurring per lightning stroke increases rapidly if the rainfall accompanying the lightning is less than about 2 or $3 \mathrm{~mm}$ [Rorig and Ferguson, 1999; Dowdy and Mills, 2012b].

Many previous studies have examined thunderstorm and severe thunderstorm occurrence in relation to localised atmospheric conditions throughout various regions of the world. With a specific focus on Australia, Allen et al. [2014] reported that high values of convective available potential energy (CAPE) and vertical wind shear are associated with a high chance of severe thunderstorm occurrence, based on reanalyses and climate simulations with a spatial grid spacing of $50 \mathrm{~km}$ in latitude and longitude. In relation to larger-scale atmospheric conditions, a number of recent studies have found that significant relationships occur between lightning occurrence and large-scale modes of variability such as the El Niño-Southern Oscillation (ENSO) [e.g., Chronis et al. 2008; Allen and Karoly 2014]. Studies such as these show that variations in large-scale environmental conditions (e.g., those associated with ENSO) can influence thunderstorm activity in some cases. This suggests that it might be possible to find large-scale indicators of lightning activity that are of a similar resolution to that of current global climate models (GCMs), i.e., with daily temporal resolution and about 1 or 2 degrees horizontal grid spacing.

Dry lightning is typically associated with thunderstorms that do not produce severe impacts such as heavy rainfall (i.e., more characteristic of non-severe thunderstorms than wet lightning), providing motivation for examining atmospheric conditions specific to dry lightning. This study is novel in that it examines large-scale environmental conditions favourable to the occurrence of dry lightning, intended for direct application to GCM output.

\section{DATA AND METHODS}

Lightning data were obtained throughout Australia from the commercial provider Global Position and Tracking System (GPATS) for the period from 2002 to 2013 (defining the study period) based on the time of arrival of the lightning discharge signal at a network of three or more radio receivers (e.g., Cummins and Murphy [2009]). The data represent individual lightning strokes, noting that a single lightning flash can consist of multiple strokes.

The ERA-Interim reanalysis [Dee et al. 2011] are used to examine various different atmospheric quantities, based on a grid of 1.5 degree spacing in both latitude and longitude. For each of these grid cells, the daily number of lightning strokes is counted, then classified as either a dry or wet lightning day based on a daily average rainfall threshold of $2.5 \mathrm{~mm}$ within the given gridded region. Rainfall data based on satellite observations are used from the Tropical Rainfall Measuring Mission (TRMM: Kummerow, et al. [1998]).

Nine atmospheric variables (Table 1) are examined as potential large-scale indicators of lightning occurrence. These variables consist of temperature and moisture measures at various pressure levels, a temperature gradient measure (as a potential indicator of frontal systems) and geostrophic vorticity at $500 \mathrm{hPa}$ as a potential indicator of large-scale conditions favourable to the occurrence of extratropical cyclones [Dowdy et al. 2013]. The variables representing air temperature at $500 \mathrm{hPa}$ and $250 \mathrm{hPa}$ are multiplied by -1 to indicate the potential for instability in relation to lower altitudes. It is noted that it is currently not well known how much lightning (dry or wet) is associated with synoptic-scale systems such as extratropical cyclones or fronts, with relatively few example of studies discussing this previously in the literature (e.g., Chambers et al. [2014] and Dowdy and Kuleshov [2014]).

To allow direct comparison between the nine variables (listed in Table 1), daily average values of individual variables at each grid point are converted to percentile values based on the entire study period (from 2002 to 2013), such that all of the nine variables use a single consistent scale (i.e. a scale ranging from 0 to 100). This percentile-based method is used here, rather than using other normalisation methods, as when applied to GCMs it provides a form of quantile-quantile bias correction (as demonstrated previously for large-scale atmospheric indicators [Dowdy et al. 2013]). 
Dowdy, Large-scale modelling of environments favourable for dry lightning occurrence

Table 1. The nine atmospheric variables examined here for potential use in indicating dry lightning activity.

\begin{tabular}{ll} 
1. & Air temperature $850 \mathrm{hPa}$ \\
\hline 2. & Air temperature $700 \mathrm{hPa}$ \\
\hline 3. & Air temperature $500 \mathrm{hPa}(*-1)$ \\
\hline 4. & Air temperature $250 \mathrm{hPa}(*-1)$ \\
\hline 5. & Specific humidity: $850 \mathrm{hPa}$ \\
\hline 6. & Specific humidity: $700 \mathrm{hPa}$ \\
\hline 7. & Specific humidity: $500 \mathrm{hPa}$ \\
\hline 8. & Surface Temperature $\mathrm{Gradient}:$ from +3 to -3 degrees longitude \\
\hline 9. & Geostrophic vorticity: $500 \mathrm{hPa}$
\end{tabular}

Every third year of the study period (from 2002 to 2013) is used for cross-validation (i.e. the years 2004, $2007,2010,2013$ ). To reduce the risk of overfitting, this portion of the data was kept completely independent from the training period (i.e., the years 2002, 2003, 2005, 2006, 2008, 2009, 2011, 2012).

To compare the nine variables against each other, a quantity, $Q$, is constructed based on combining three of the nine different atmospheric variables (i.e. $9 * 8 * 7=504$ possible combinations) with various different weighting factors as shown by Equation 1. The weightings (of 4, 3 and 2) were selected with the aim of allowing some variation in the relative influence of each variable.

$$
Q=4 * V_{1}+3 * V_{2}+2 * V_{3}
$$

where $V_{l}, V_{2}$ and $V_{3}$ are three different atmospheric variables (from Table 1).

The study method is based on finding a threshold value, $Q_{\text {thresh }}$, for which two thirds of the days with lightning correspond to $Q \geq Q_{\text {thresh }}$ (i.e., the number of 'Hits' is always twice as large as the number of 'Misses' for the training period). Consequently, the Probability of Detection (POD, calculated as the number of Hits divided by the total number of events, as shown by Equation 2) is always equal to 0.67 during the training period. The days with $Q \geq Q_{\text {thresh }}$ for which lightning does not occur are counted as 'False Alarms' for the training period. The combination of three variables (based on Equation 1) with the smallest number of False Alarms in the training period is found for each individual location. This combination of three variables (and the value of $Q_{\text {thresh }}$ ) in then applied to the third of the study period that was set aside for independent crossvalidation. Days in the cross-validation period for which $Q \geq Q_{\text {thresh }}$ are counted as Hits if lightning occurred, or False Alarms if lightning did not occur. Days in the cross-validation period for which $Q<Q_{\text {thresh }}$ are counted as Misses if lightning occurred. The skill of the method is assessed for the cross-validation period, based on the POD and the Critical Success Index (CSI, calculated as the number of Hits divided by the sum of the number of Hits, Misses and False Alarms, as shown by Equation 3).

$$
\begin{aligned}
& \text { POD }=\text { Hits } /(\text { Hits }+ \text { Misses }) \\
& \text { CSI }=\text { Hits } /(\text { Hits }+ \text { Misses + False Alarms })
\end{aligned}
$$

Simulations of historical and future climate were obtained from the ACCESS1.0 GCM for the CMIP5 set of model output. The future simulations are based on the RCP8.5 forcing pathway, representing a relatively high emissions case where greenhouse gas concentrations continue to rise towards the end of the $21^{\text {st }}$ Century. For further details on these simulations see Collier and Uhe [2012].

\section{RESULTS}

\subsection{Comparison of variables}

Figure 1 shows the results of applying the study method for the period 2005 to 2013 throughout Australian land regions. The number of times that a particular variables is used is presented, weighted by the factors 
shown in Equation 1 and summed for any grid point in four different regions (northwest ' $\bullet$ ', northeast '*', southwest ' $\square$ ' and southeast ' $\Delta$ ') with these regions separated by boundary lines of $25^{\circ} \mathrm{S}$ in latitude and $135^{\circ} \mathrm{E}$ in longitude.

There are some differences between regions (particularly between the northern and southern regions) as well as between dry and wet lightning, in terms of which variables are preferable to use. For example, the measures of temperature are generally more heavily weighted for dry lightning than wet lightning, and the measures of moisture (i.e., specific humidity at various pressure levels) are generally more heavily weighted for wet lightning than dry lightning. However, in general there are broad similarities between dry and wet lightning in all of the different regions examined here. The similarities between dry and wet lightning include variables that have very low weightings, such as air temperature at $250 \mathrm{hPa}$ (variable \#4), specific humidity at $500 \mathrm{hPa}$ (variable \#7: particularly in the case of dry lightning) as well as the variables for fronts (variable \#8) and cyclones (variable \#9). Temperature at $700 \mathrm{hPa}$ (variable \#2) generally has a very low weighting, with the exception of the cases for dry lightning in the southern regions potentially indicative of high-based thunderstorms being conducive to dry lightning, while noting that the $850 \mathrm{hPa}$ temperature (variable \#1) is weighted higher than the $700 \mathrm{hPa}$ temperature for dry lightning in all four regions. Examining the variables that are strongly weighted in all regions suggests that lightning (dry or wet) in Australia generally requires high values of both temperature lapse and moisture content at some of the levels examined here, particularly as indicated by the 850 and $500 \mathrm{hPa}$ temperature measures and the $850 \mathrm{hPa}$ specific humidity (variables $\# 1$, $\# 3$ and \#5, respectively).
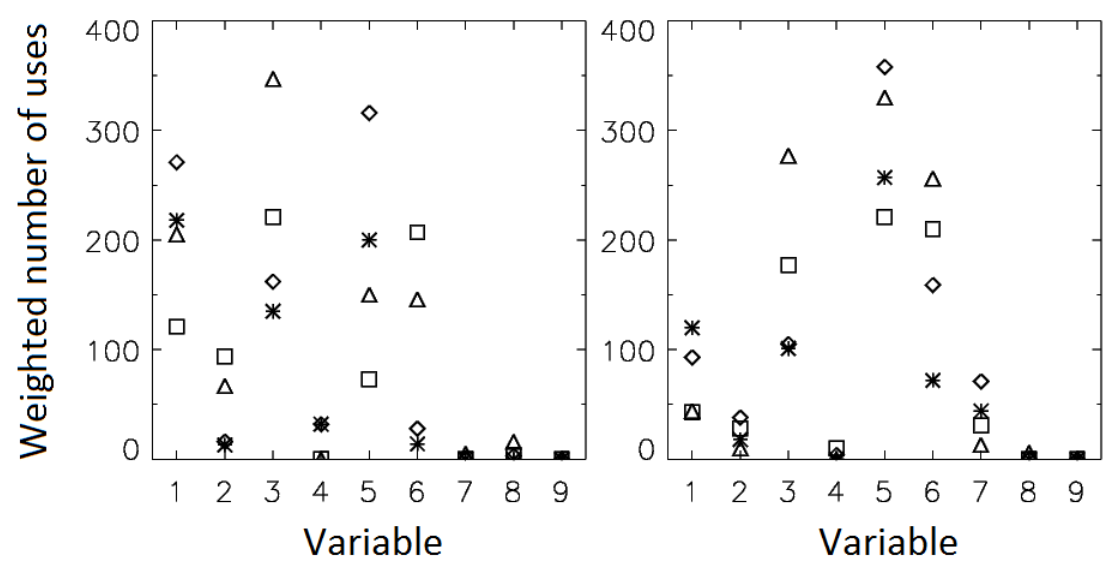

Figure 1. The ability of nine different atmospheric variables to indicate large-scale atmospheric conditions favourable to dry (left panel) and wet (right panel) lightning days. The number of times that a variable is selected at locations within the study region is shown, with the weighting factors applied as described in Equation 1. This is presented for four regions separated by boundary lines of $25^{\circ} \mathrm{S}$ in latitude and $135^{\circ} \mathrm{E}$ in longitude (northwest ' $\checkmark$ ', northeast '*', southwest ' $\square$ ' and southeast ' $\Delta$ '). The reference numbers for the nine variables are as listed in Table 1 .

Given the broad similarities between dry and wet lightning in terms of their more heavily weighted variables throughout Australia (from Fig. 1), a modified version of the method was tested using a combination of the $850-500 \mathrm{hPa}$ temperature lapse and a moisture measure at $850 \mathrm{hPa}$, as represented by the Total Totals Index (TTI: equation 4), with Equation 1 simplified as shown in Equation 5.

$$
T T I=T_{850}-2 * T_{500}+T d_{850}
$$

where $T_{850}$ is the temperature at $850 \mathrm{hPa}, T_{500}$ is the temperature at $500 \mathrm{hPa}$ and $T d_{850}$ is the dewpoint temperature at $850 \mathrm{hPa}$.

$$
Q=T T I
$$

As shown in Fig. 2, the TTI provides a reasonably good representation of large-scale conditions favourable to the occurrence of days on which lightning occur (hereafter, lightning days), with CSI values of the order of 0.3-0.4 and POD values of about 0.6-0.7, based on the cross-validation period. Overfitting does not appear to be occurring given that the POD values for lightning days for the cross-validation period (Fig. 2 lower left panel) are typically within $\pm 20 \%$ of the POD values of 0.67 for the training period. The POD values for lightning strokes are notably higher (typically above about 0.8 , while noting a considerable number of 
regions with values above 0.9), indicating that the lightning days identified by the method (i.e. the Hits) have more lightning strokes on average than the lightning days that are not identified by the method (i.e. the Misses). The spatial variability of the lightning strokes identified by this method (Fig. 2 lower right panel) is similar to the observed climatology based on satellite lightning observations in the Australian region [Dowdy and Kuleshov 2014], noting that the TTI has not previously been applied to examine the climatology of lightning activity throughout Australia.
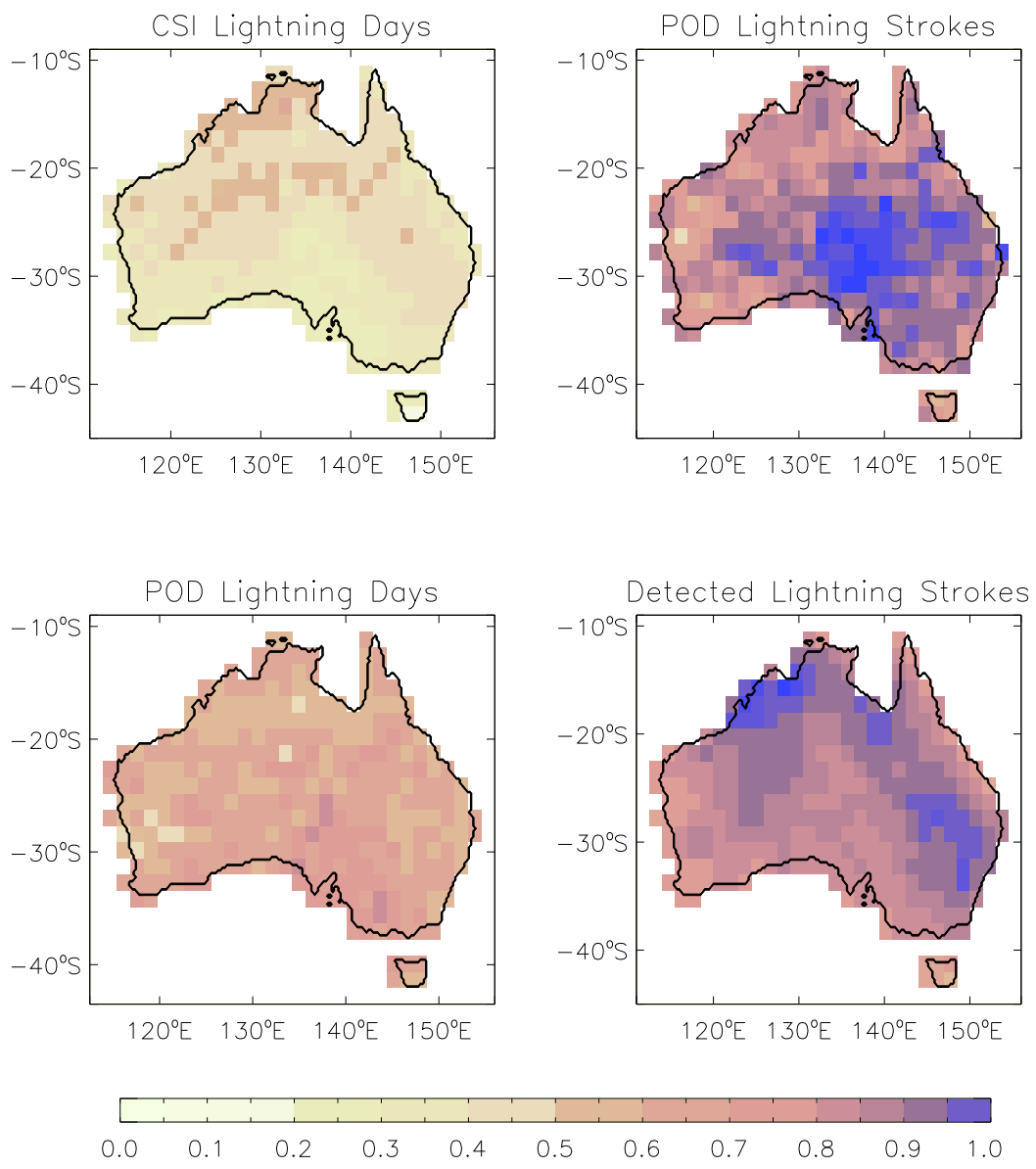

Figure 2. The ability of the study method to indicate large-scale atmospheric conditions favourable to lightning activity. CSI (upper left) and POD (lower left) values are shown for lightning days, as well as POD values for lightning strokes (upper right). The number of detected lightning strokes, $n$, is shown (lower right), scaled by $\log _{e}(n) / 13$ to show spatial variability using the colour-bar scale provided.

\subsection{Projections of future climate}

The ACCESS1.0 climate model is used to examine large-scale environments favourable to lightning activity (based on TTI) in combination with rainfall simulations for the current and projected future climate. As rainfall simulated by climate models can have a range of biases associated with it, the simulated rainfall used here is quantile-quantile matched to the $2.5 \mathrm{~mm}$ rainfall threshold based on observations (using the frequency of occurrence of daily rainfall amounts from TRMM). The percentile thresholds of the TTI based on reanalyses (as calculated in the previous section for each individual grid point) are applied to the GCM output to indicate large-scale conditions favourable to lightning occurrence. Days on which the value of $Q$ (i.e., $Q=T T I$, from Equation 5) is above its threshold value (i.e. $Q>Q_{t h r e s h}$ ) in the model output are classed as favourable dry lightning days if the model rainfall (with quantile-quantile correction applied) is below the value representing $2.5 \mathrm{~mm}$ of rainfall. These conditions are examined here for an historical period (19751999), as well as for a future period (2086-2100) representing higher atmospheric greenhouse gas concentrations (based on the RCP8.5 pathway).

Figure 3 shows the simulated number of dry days (i.e. rainfall less than $2.5 \mathrm{~mm}$ ) for the historical climate (first column of panels from the left), as well the projected change based on the future climate minus the historical climate (second column of panels from the left). Figure 3 also shows the simulated number of 
favourable dry lightning days for the historical climate (third column of panels from the left), as well as the projected change (fourth column of panels from the left). This is shown for four seasons (December, January and February: DJF; March, April and May: MAM; June, July and August: JJA; and September, October and November: SON).

The simulated number of dry days for the historical climate shows more dry days in the south than the north during summer, and more dry days in the north than the south during winter. The projected change in the number of dry days indicates some spatial and seasonal variation, including a region of decrease in the north during summer and a region of small magnitude increase in the southeast during spring. The simulated number of favourable dry lightning days is typically higher during summer than winter, with the exception of the far southern coastal regions and Tasmania. The projected change in the number of favourable dry lightning days shows considerable spatial variation throughout Australia, with regions of increases and decreases apparent in each individual season.
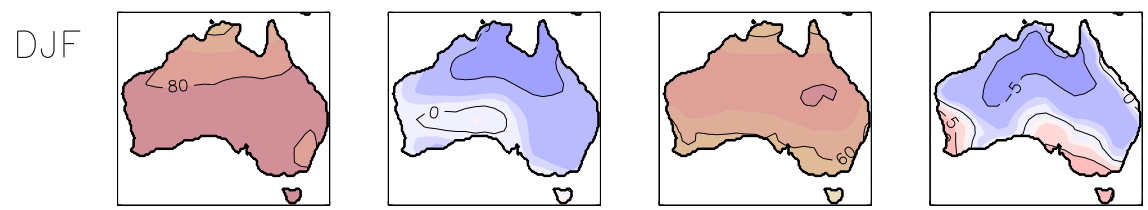

MAM
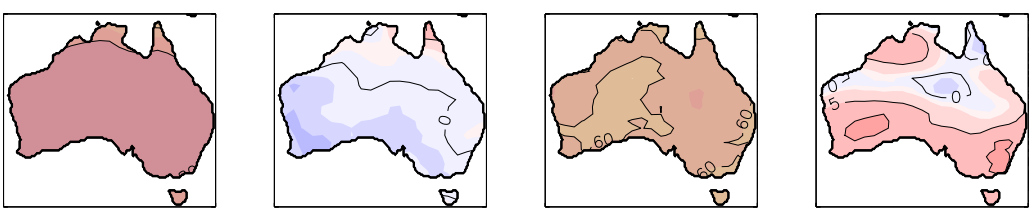

JJA
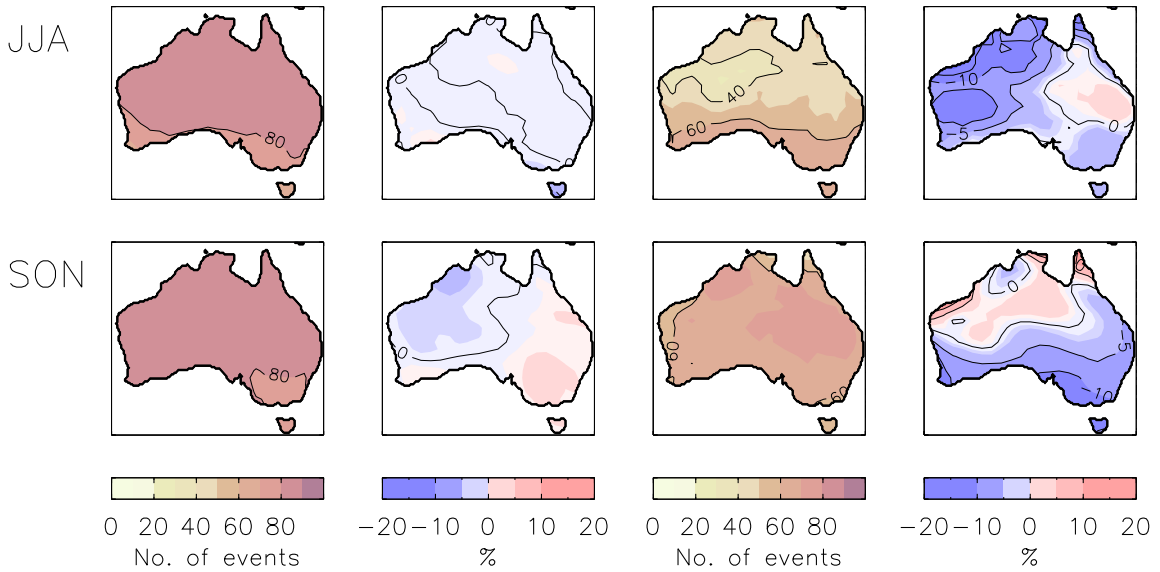

Figure 3. The simulated number of dry days for the historical climate (first column of panels from the left), as well the percentage change based on the future climate minus the historical climate (second column of panels from the left). Also shown is the simulated number of favourable dry lightning days for the historical climate (third column of panels from the left), as well as the percentage change based on the future climate minus the historical climate (fourth column of panels from the left). This is shown for each of four seasons: December, January and February (DJF, top row of panels); March, April and May (MAM: second to top row of panels); June, July and August (JJA: third to top row of panels); and September, October and November

(SON: fourth to top row of panels).

\section{CONCLUSION}

The influence of increasing greenhouse gas concentrations on dry-lightning activity has not previously been examined for any region of the world. A method was examined here for indicating large-scale conditions favourable to the occurrence of dry lightning. It was developed based on the combination of observations and reanalyses, then applied to GCM simulations of current and future climate. The initial results presented here indicate considerable spatial variability of the influence of increasing greenhouse gasses on the occurrence of dry lightning.

The study method provides considerable scope for subsequent work, including further examinations of the differences between dry and wet lightning environments, as well as the possible use of different data sets 
Dowdy, Large-scale modelling of environments favourable for dry lightning occurrence

(e.g., utilising the range of different lightning observations now available). Different methods and models could also be examined, such as other GCMs or downscaling techniques (noting the considerable uncertainty in future projections of rainfall in some regions and seasons of Australia [CSIRO and BoM 2015]).

\section{ACKNOWLEDGMENTS}

This work was supported by the Australian Climate Change Science Program.

\section{REFERENCES}

Allen, J.T., Karoly, D.J. and Walsh, K.J. (2014). Future Australian severe thunderstorm environments. Part I: A novel evaluation and climatology of convective parameters from two climate models for the late twentieth century. Journal of Climate, 27: 3827-3847.

Allen, J.T. and Karoly, D.J. (2014). A climatology of Australian severe thunderstorm environments 19792011: inter-annual variability and ENSO influence. International Journal of Climatology, 34: 81-97.

Chronis, T.G., et al. (2008). Global lightning activity from the ENSO perspective. Geophys. Res. Lett., 35 : L19804, doi:10.1029/2008GL034321.

Chambers, C.R.S., et al. (2014). Precipitation changes due to the introduction of eddy-resolved sea surface temperatures into simulations of the "Pasha Bulker" Australian east coast low of June 2007. Meteorology and Atmospheric Physics, 125: 1-15.

Collier, M. and Uhe, P. (2012). CMIP5 datasets from the ACCESS1.0 and ACCESS1.3 coupled climate models. CAWCR Technical Report No. 059. The Centre for Australian Weather and Climate Research.

CSIRO and Bureau of Meteorology, 2015: Climate Change in Australia Information for Australia's Natural Resource Management Regions: Technical Report, CSIRO and Bureau of Meteorology, Australia (available from www.climatechangeinaustralia.gov.au).

Cummins, K.L. and Murphy, M.J. (2009). An overview of lightning locating systems: History, techniques, and data uses, with an in-depth look at U.S. NLDN. IEEE Trans., Electromagn. Compat., 51: 499518.

Dee, D.P., et al. (2011): The ERA-Interim reanalysis: Configuration and performance of the data assimilation system. Q. J. R. Meteorol. Soc., 137: 553-597.

Dowdy, A.J. and Mills, G.A. (2012a). Characteristics of lightning-attributed fires in south-east Australia. Int. J. of Wildland Fire, 21: 521-524, doi.org/10.1071/WF10145.

Dowdy, A.J. and Mills, G.A. (2012b). Atmospheric and fuel moisture characteristics associated with lightning-attributed fires, J. Appl. Meteorol. Climatol., 51: 2025-2037, doi: 10.1175/JAMC-D-110219.1.

Dowdy, A.J., Mills, G.A. and Timbal, B. (2013). Large-scale diagnostics of extratropical cyclogenesis in eastern Australia. International Journal of Climatology, 10: 231802327, doi:10.1002/joc.3599.

Dowdy, A.J. and Kuleshov, Y. (2014). Lightning climatology of Australia: temporal and spatial variability. Australian Meteorological and Oceanographic Journal, 64: 103-108.

Kasischke, E.R., Rupp, T.S. and Verbyla, D.L. (2006). Fire trends in the Alaskan Boreal Forest. In 'Alaska's changing boreal forest'. (Eds FS Chapin, M Oswood, K van Cleve, L Viereck and D Verbyla) pp. 285-301. (Oxford University Press: US).

Kummerow, C., Barnes, W., Kozu, T., Shiue, J. and Simpson, J. (1998). The tropical rainfall measuring mission (TRMM) sensor package. Journal of atmospheric and oceanic technology, 15: 809-817.

Rorig, M.L. and Ferguson, S.A. (1999). Characteristics of Lightning and Wildland Fire Ignition in the Pacific Northwest. Journal of Applied Meteorology, 38: 1565-1575.

Wotton, B.M., Stocks, B.J. and Martell, D.L. (2005). An index for tracking sheltered forest floor moisture within the Canadian Forest Fire Weather Index System. International Journal of Wildland Fire, 14: 169-182. 